at the disposal of employers, even outside working hours. This relationship is reversed when the worker has more seniority in the labor relationship.

Conclusions The results presented here are the outcome of a study in which unionized workers, presumably organized and with access to information, participated. Despite this, results reveal that the law and the policies developed for the sector do not protect domestic workers' health, as they do not consider the particularities of the sector. These results reflect the need to continue investigating the particularities of their working conditions to prevent their negative impact on health.

\section{P-348 THE ROLE OF AN OCCUPATIONAL HEALTH SERVICE IN THE RETURN TO WORK FROM WORKERS DISCOURSE ANALYSIS}

${ }^{1}$ Fernanda Miranda, Vivian Mininel, Karen Freitas. 'Universidade Federal de São Carlos, Brazil

\subsection{6/OEM-2021-EPI.281}

Introduction The Brazilian Public Healthcare System offers an occupational health service (OHS) regulated from the Primary Health Care to assist work injuries and diseases and collaborate to return-to-work (RTW), to ensure workplace accommodations for the rehabilitated worker.

Objective To understand the role of the OHS in the RTW process from the perspective of workers assisted by this service.

Methods

Qualitative research We interview eight workers assisted by OHS in 2017-2018 after discharge and RTW. We analyzed the speeches based on Discourse Analysis and interpreted them based on RTW and Psychodynamics of Work theoretical approaches. Results OHS was considered helpful in the RTW mainly in the physical and psychological health recovery. Besides, it helped to guarantee workers' rights regarding to the social security benefits and the employer's responsibilities. However, workers highlighted the need for improvement inside OHS team communication and between them and workers, as well negotiations with the employer to workplace accommodations and better security conditions of work.

Conclusion OHS was considered helpful for individual recovery, but limited for RTW. Even so, workers recognize the relevance of this service in difficult and complex moments such as RTW, and also the protagonism of it when compared to other stakeholders. Considering the potential for articulations of the OHS we suggest it mediates actions together with workers and stakeholders to improve the RTW process.

\section{P-349 CHALLENGES OF RETURN-TO-WORK AFTER WORK- RELATED SICK LEAVE: FROM WORKERS PERSPECTIVES}

${ }^{1}$ Fernanda Miranda, Vivian Mininel, Karen Freitas. 'Universidade Federal de São Carlos, Brazil

\subsection{6/OEM-2021-EPI.282}

Introduction Return-to-work (RTW) is a complex process that involves many sectors and stakeholders including worker participation. RTW should consider biopsychosocial aspects of workers and workplace changes with stakeholders' participation to ensure adaptation and sustainability of the job.
Objective to identify RTW challenges from workers' perspectives after work-related sick leave.

Methods Qualitative research. We interview workers who were victims of occupational diseases or accidents and were treated by a Brazilian public occupational health. We analyzed the speeches considering theoretical and methodological approaches of RTW, Psychodynamics of Work, and Discourse Analysis.

Results RTW is a difficult experience for workers, mainly caused for miscommunication and non-articulation of stakeholders and sectors involved. RTW triggers negative feelings and distress in the workers such as humiliation, revolt, and even feeling of guilt due to sick leave. Besides, workers experience fear of retaliation and stigmatization of their employer or co-workers for their new condition and receive rare or no support in this sense. Discourse analysis shows lacking support from stakeholders and the invisibility of workers during return to work that walks alone in this path. Government sectors (as insurance and healthcare systems) do not mediate RTW and workplace accommodations rely on workers' demand in an unfair and unbalanced negotiation with the employer.

Conclusion There is an urgent need to review the RTW process in Brazil focusing on a collaborative model between sectors, stakeholders, and the worker looking to a more comprehensive perspective and more effective results.

\section{P-350 SOCIO-OCCUPATIONAL INEQUALITIES IN POTENTIAL WORK-RELATED EXPOSURE TO SARS-COV-2}

${ }^{1}$ Narges Ghoroubi, Emilie Counil, Ariane Pailhé, Myriam Khlat. ${ }^{1}$ French Institute for Demographic Studies (INED), France

\subsection{6/OEM-2021-EPI.283}

Introduction The risk of contracting COVID-19 is not uniform across occupations. Certain workers, exposed to diseases/infections, interfacing with the public/colleagues, unable to work from home, and without appropriate personal protective equipment are likely to experience higher workplace exposure to SARS-CoV-2.

Objective To describe the proportion of workers potentially exposed to coronavirus in each occupation under 'routine' working conditions, as well as a baseline socio-demographic profile of these workers in France.

Methods We combined two French cross-sectional populationbased surveys: 'Working Conditions' (CT-2013) and 'Medical Surveillance of Occupational Risk Exposure' (Sumer-2017) to quantify 'exposure to infectious agents', 'face-to-face contact with the public' and 'working with colleagues'. We then identified the most exposed occupations before the first lockdown and built an exposure matrix. Finally, we described other socio-demographic characteristics (age, sex, occupational group, educational level, income level, origin) of the workers with the highest potential exposure to COVID-19.

Results Before the first lockdown, 42\% (11 million) of French workers were exposed to at least two COVID-19 occupational exposure factors. While most exposed workers are in the health care sector, other occupations such as social workers, hotel/restaurant employees, army/police officers, firefighters, hairdressers, and teachers also have a high proportion of exposed workers. Middle age participants, females, unskilled employees, those with post-secondary non-tertiary education, 